\title{
Intangibilidade em empresas inovadoras no Brasil: um estudo com base no Índice Brasil de Inovação
}

\section{Intangibility in innovative companies in Brazil: a study based on the Brazil Innovation Index}

\author{
EVANDRO LUIZ GAFFURI* \\ RENATO DE BIANCHI** \\ JULIANO DOMINGUES SILVA*** \\ DEISY CRISTINA CORREA IGARASHI****
}

\section{RESUMO}

Com a obrigatoriedade em registrar os ativos intangíveis nas demonstrações financeiras, estudos têm buscado relacionar tal prática com outros fatores, a fim de compreender a influência deles na inovação e no desempenho das organizações. Este estudo possui caráter descritivo, qualitativo e quantitativo e analisou 103 empresas do segmento de novo mercado listadas na bolsa de valores pela $\mathrm{BM} \& \mathrm{FBovespa}$. O objetivo consiste em compreender se os ativos intangíveis registrados nas demonstrações financeiras das empresas brasileiras configuram vínculo com a inovação e a lucratividade. Os resultados obtidos reforçaram a constatação de outros artigos de que o grau de intangibilidade não possui relação com o grau de inovação, assim como a intangibilidade de uma empresa não apresenta relação com sua lucratividade. Foi evidenciado que investimentos em pesquisa e desenvolvimento possuem correlação positiva com o lucro líquido e que investimentos em relacionamento com clientes e fornecedores estão correlacionados positivamente ao patrimônio líquido, todavia sua

Mestre em Administração (UEM - 2016). elgaffuri@gmail.com .

** Especialização em Administração de Empresas (FGV - 2012). rdb.renato@gmail.com .

*** Universidade Estadual de Maringá. Doutorando do Programa de Pós-graduação em Administração (UEM). jdomingues8@gmail.com .

**** Universidade Estadual de Maringá. Doutora em Engenharia de Produção (UFSC - 2009), Pós-doutorado em Administração (UEM - 2016). deisyigarashi@gmail.com . 
relação não apresentou significância nos testes de regressão. Dessa forma, este estudo contribui para a compreensão da influência dos ativos intangíveis no contexto organizacional, bem como ao utilizar-se da correlação para identificar essas influências.

Palavras-chave: inovação; intangibilidade; Índice Brasil de Inovação.

\section{Abstract}

With the requirement to record the intangible assets in the financial statements, studies have attempted to relate this practice with other factors, in order to understand the influence of intangible assets on the innovation and performance of organizations. This study has descriptive, qualitative and quantitative, studied 103 companies from the new market segment listed on the stock exchange BM\&FBovespa. The purpose of the work consists to understand if the registered intangible assets in the financial statements of Brazilian companies configure link with innovation and profitability. The results obtained reinforced the finding of other articles that the intangibility degree has no relationship with the innovation degree, as well as the intangibility of a company is unrelated to its profitability. It was evidenced that investments in research and development have positive correlation with net income and that investments in relationships with customers and suppliers are positively correlated to shareholders' equity, but their relationship did not show significance in regression testing. In this way, the present study contributes to the understanding of the influence of intangibles in the organizational context, as well as using correlation to identify these influences.

Keywords: innovation; intangibility; Brazil Innovation Index.

\section{INTRODUÇÃo}

A aprovação da Lei n. 11.638/2007 (BRASIL, 2007), ao estabelecer que os registros do intangível no ativo não circulante sejam apresentados obrigatoriamente no Balanço Patrimonial, torna explícita a percepção de Kayo et al. (2006) de que os intangíveis alavancam elementos que são responsáveis pelas mudanças financeiras e operacionais das empresas e exercem influência em seus valores de avaliação junto ao mercado. Adicionalmente o IAS 38, no Brasil representado via CPC 04 (R1) (CPC, 2010), designa o adequado tra- 
tamento contábil aos ativos intangíveis, além de especificar aspectos quanto à mensuração e à divulgação deles junto às notas explicativas e às demonstrações financeiras.

A título de ilustração das classes de ativos intangíveis que são abrangidos pelo CPC 04 (R1) (CPC, 2010), pode-se mencionar as seguintes: softwares, licenças e franquias, patentes, ativos intangíveis em desenvolvimento e outros. Ademais, os elementos que compõem cada classe de ativo intangível, bem como a própria classe podem variar de empresa para empresa e são comumente associados à inovação.

Os ativos intangíveis por vezes são interpretados como competências e capacidades geradas pela aprendizagem e que têm por resultados a própria inovação (ARRIGHETTIA; LANDINIB; LASAGNIA, 2014; OCDE, 2006; MONTRESOR; PERANI; VEZZANI, 2014). Portanto, conforme defendem Tsai e Lub (2012), englobam a capacidade dinâmica da organização em utilizar a mão de obra qualificada, o know-how, as competências dos especialistas, empregados e clientes e o reconhecimento da marca e da cultura organizacional para gerar valor e consequentemente inovação, seja em questões processuais, seja na criação de marcas e patentes.

Alinhado a essa percepção, a Organização para a Cooperação e Desenvolvimento Econômico (OCDE) (2006) pondera, em muitos casos, que a estatística de criação de patentes e marcas é associada como indicadores de inovação relevantes. Segundo a OCDE (2006), a inovação ocorre em diversos setores da economia e sua essência é tentar assegurar o posicionamento competitivo e maior vantagem perante o mercado por meio de inovações, desde simples mudanças técnicas até a criação de novos mercados.

Além disso, até meados de 2005 o Brasil demandava estabelecer formas para medir critérios da inovação, ação que passou a ser implementada a partir da discussão sobre as políticas de gestão da inovação no Brasil via Lei Federal n. 10.973/2004 (Lei de Inovação Tecnológica - LIT). Matias-Pereira e Kruglianskas (2005) ponderam que experiências da Coreia do Sul, França, Estados Unidos e Japão influenciam os debates sobre o tema no Brasil. Ademais o Índice Brasil de Inovação (IBI), desde sua primeira edição, atingiu o seu principal objetivo: testar interesse de adesão das empresas. 
O IBI fomenta a produção de indicadores primários em bases da Pesquisa de Inovação - PINTEC (IBGE, 2013), adequando possíveis vieses como, por exemplo, o tamanho das empresas (QUADROS; FURTADO, 2007). Além disso, o IBI, conforme demonstrado neste estudo, classifica e enquadra as empresas entre quatro grupos de intensidade tecnológica, analisando-os com base em dois macroindicadores: o indicador agregado de esforço e o indicador agregado de resultado. O Índice Brasil de Inovação é relevante neste estudo, principalmente no que tange à seleção dos indicadores, pois os que são apresentados no Quadro 2 deste artigo possuem relação direta com os intangíveis vislumbrados e segmentados em quatros grupos.

Dadas essas noções da relação conceitual próxima entre inovação e intangíveis, o principal problema proposto por esta pesquisa é identificar se há uma relação direta entre os intangíveis, a inovação e os resultados de lucratividade das empresas, isto é, aquelas que investem mais em intangíveis e inovações possuem maior lucratividade? Para tanto, foram apresentadas oito hipóteses que buscaram compreender se os investimentos em inovação possuem relação diretamente positiva com os resultados da organização em seu lucro líquido; se o ativo intangível possui relação diretamente positiva com a lucratividade da empresa; e se a diversificação dos intangíveis possui relação positiva com a lucratividade das empresas.

O artigo é apresentado por meio de uma pesquisa descritiva, de natureza quantitativa e qualitativa, de procedimento bibliográfico e documental com foco no objetivo principal de compreender se os intangíveis registrados nas demonstrações financeiras das empresas brasileiras configuram vínculo com a inovação e a lucratividade. $\mathrm{O}$ universo das empresas foi retirado da análise das notas explicativas da BM\&FBovespa (BM\&FBOVESPA, [s.d.]), compreendendo inicialmente um total de 529 empresas, as quais foram reduzidas com as devidas justificativas, tais como: não serem do segmento do novo mercado; não possuírem quadro de intangível; não apresentarem segmento bem definido; e outros demonstrados na seção de procedimentos metodológicos. Inicialmente será tratado o referencial teórico, englobando tópicos como inovação, intangibilidade, oportunidade e Índice Brasil de Inovação. Em seguida tem-se a seção de metodologia e logo após é apresentada a seção representada pela 
análise dos resultados. A última seção trará à luz a discussão e a conclusão dos resultados apresentados.

\section{REFERENCIAL TEÓRICo}

\subsection{Inovação e oportunidade}

A inovação tem sua construção histórica vinculada às teorias de Schumpeter (1950), o qual foi um dos primeiros autores a buscar a engenhosidade das inovações. Ele afirmava que o empreendedor pode, e deve, de maneira significativa criar imperfeições, a fim de causar desequilíbrio no mercado, para que consequentemente possa introduzir inovações, gerando a destruição criativa.

A inovação torna-se a base do crescimento econômico e é responsável por mais da metade do PIB dos países desenvolvidos. Essa relação é chamada de "desmaterialização da produção" (GUIMARÃES, 2011). Além disso, o crescimento e a competitividade no meio econômico dependem, sobretudo, do conhecimento; ou seja, busca-se cada vez mais um insumo que proporcione diferencial aos insumos clássicos como terra, capital e trabalho (GUIMARÃES, 2011). Nesse contexto, Clemente e Caulliraux (2007) consideram que tem sido atribuída maior ênfase à inovação, fator que se configura como determinante de diferenciação, e que atua como requisito mínimo para a sobrevivência no mercado. Assim, esses autores consideram que a inovação auxilia a sustentar vantagens competitivas e faz com que as organizações se mantenham na liderança do mercado. Todavia, para que esse cenário perdure é necessário que as corporações introduzam mudanças constantes, com rápida velocidade, e que arquem em muitos casos com a obsolescência dos próprios produtos e serviços (CLEMENTE; CAULLIRAUX, 2007).

A OCDE (2006) pondera que a inovação pode ser considerada como as mudanças planejadas com a intenção de melhorar o desempenho da empresa. De tal forma, essa definição assume a interpretação de dados de inovação conforme o Oslo Manual - Guidelines for Collecting and Interpreting Innovation Data (OCDE, 2005, p. 146), o qual considera que a "inovação é a implementação de um produto (bem ou serviço), processo ou método de marketing novo ou signi- 
ficativamente melhorado, ou um novo método organizacional em práticas de negócio, local de trabalho ou relações externas".

Adicionalmente o OCDE (2006) destaca os seguintes aspectos característicos à inovação: (a) apresenta incertezas, ou seja, não se pode afirmar com certeza os resultados obtidos; (b) necessita de investimento; (c) pode ser oriunda de um resíduo de transbordamentos, ou seja, há casos em que a empresa que inova não se apropria por completo de sua inovação, fazendo com que corporações externas explorem oportunidades e pratiquem outras inovações a partir de uma inovação inicial; (d) necessita da utilização de conhecimento novo; e (e) tem em sua essência a busca por um ganho de vantagem competitiva para a empresa. Com base nessas informações, têm-se as seguintes hipóteses:

H1: Os investimentos em inovação apresentam relação positiva com os resultados das organizações, este evidenciado pelo Lucro Líquido (OCDE, 2006).

H2: Os investimentos em inovação não apresentam relação positiva com os resultados das organizações, este evidenciado pelo Lucro Líquido.

Essas percepções sobre inovação estão correlacionadas com a oportunidade, uma vez que esta pode ser criada ou descoberta, dado que está presente no ambiente (ARDICHVILI; CARDOZO; RAY, 2000; KIRZNER, 2008). Todavia, Hansen, Shrader e Monllor (2011) ressaltam que em muitas pesquisas o conceito de oportunidade é dado de modo prematuro, pois raramente é acompanhado de uma definição publicada anteriormente por outro pesquisador. Nesse sentido esta pesquisa apresenta no Quadro 1 algumas possibilidades quanto à definição de oportunidade listadas por Hansen, Shrader e Monllor (2011). 
Quadro 1: Seis definições de oportunidade

\begin{tabular}{|l|l|}
\hline Definição de oportunidade & $\begin{array}{l}\text { Quantidade } \\
\text { de artigos } \\
\text { que definiram } \\
\text { de tal forma }\end{array}$ \\
\hline $\begin{array}{l}\text { 1. Uma oportunidade é a possibilidade de se introduzir um } \\
\text { novo produto ao mercado, visando ao lucro. }\end{array}$ & 11 \\
\hline $\begin{array}{l}\text { 2. Uma oportunidade é uma situação em que empreende- } \\
\text { dores veem ou criam novas estruturas meio-fins. }\end{array}$ & 3 \\
\hline $\begin{array}{l}\text { 3. Uma oportunidade é uma ideia que se desenvolve para } \\
\text { uma forma de negócios. }\end{array}$ & 4 \\
\hline $\begin{array}{l}\text { 4. Uma oportunidade é uma percepção empreendedora de } \\
\text { meios possíveis para se obterem/alcançarem benefícios. }\end{array}$ & 5 \\
\hline $\begin{array}{l}\text { 5. Uma oportunidade é uma habilidade empreendedora } \\
\text { para criar soluções para um problema. }\end{array}$ & 1 \\
\hline $\begin{array}{l}\text { 6. Uma oportunidade é a possibilidade de atender a um } \\
\text { consumidor de forma diferenciada e melhor. }\end{array}$ & 1 \\
\hline
\end{tabular}

Fonte: Adaptação de Hansen, Shrader e Monllor (2011).

Apesar de no Quadro 1 as definições listadas pelos diversos autores e compiladas por Hansen, Shrader e Monllor (2011) de modo global expressarem pouco consenso, considera-se que, no que se refere a oportunidade, nessas definições os termos em negrito relacionam-se com a inovação, tendo em vista os cinco princípios propostos pelo Manual de Oslo OCDE (2006). Logo, conforme as considerações apresentadas no âmbito desta pesquisa, a inovação é decorrente de um processo de investimento, pesquisa e desenvolvimento internos da empresa, combinação e utilização de tecnologias existentes e novos conhecimentos adquiridos. Nesse âmbito, a inovação é possível de ser medida, e uma das formas de fazê-lo é por meio do Índice Brasil de Inovação (IBI), o qual é descrito na seção seguinte.

\subsection{1 Índice Brasil de Inovação}

A constituição do IBI baseou-se em mensurar e medir a capacidade de geração de inovação das empresas brasileiras, construindo um ranking daquelas mais inovadoras. A participação das organizações no IBI é voluntária e pode gerar vantagens como a maior visibilidade para elas, valorização da marca e informação dos resultados da própria demonstração dos indicadores (FURTADO et al., 2007). 
O IBI segue como matriz metodológica e teórico-conceitual as premissas propostas pelo Oslo (2006). Os indicadores do IBI possuem como dimensão central o esforço e o resultado das atividades de inovação, e esses macroindicadores são utilizados para o cálculo do IBI, os quais possuem peso igualitário para o resultado dos indicadores (FURTADO et al., 2007), além de uma série de divisões de indicadores em nível micro (Quadro 2).

\section{Quadro 2: Indicadores IBI}

\begin{tabular}{|c|c|}
\hline Macroindicador & Microindicador \\
\hline \multirow{7}{*}{$\begin{array}{l}\text { Indicador Agregado de Esforço (IAE) } \\
\text { Conceito } \\
\text { "Atividades internas de pesquisa e desenvolvimento nas empre- } \\
\text { sas; obtenção de conhecimento por meio da aquisição de direitos } \\
\text { de propriedade intelectual; investimento no lançamento de pro- } \\
\text { dutos ou processos novos para o mercado, em pessoal qualifica- } \\
\text { do (graduados, mestres e doutores) trabalhando em pesquisa e } \\
\text { desenvolvimento e em treinamento; dispêndios com máquinas e } \\
\text { equipamentos, com software e com projeto industrial." (FURTA- } \\
\text { DO et al., 2007, p. 13) }\end{array}$} & $\begin{array}{l}\text { Investimento total em } \\
\text { Pesquisa e Desenvol- } \\
\text { vimento (P\&D) }\end{array}$ \\
\hline & $\begin{array}{l}\text { Investimento total em } \\
\text { propriedade intelectual }\end{array}$ \\
\hline & $\begin{array}{l}\text { Investimento total em } \\
\text { novos produtos }\end{array}$ \\
\hline & $\begin{array}{l}\text { Investimento total em } \\
\text { novos serviços }\end{array}$ \\
\hline & $\begin{array}{l}\text { Investimento total em } \\
\text { treinamento }\end{array}$ \\
\hline & $\begin{array}{l}\text { Investimento total em } \\
\text { máquinas e equipa- } \\
\text { mentos }\end{array}$ \\
\hline & \\
\hline \multirow{5}{*}{$\begin{array}{l}\text { Indicador Agregado de Resultado (IAR) } \\
\text { Conceito } \\
\text { “Compõem-se de resultados econômicos, medidos pela capacida- } \\
\text { de da empresa de alavancar sua receita líquida total de vendas } \\
\text { com produtos novos para ela mesma, o mercado nacional e para } \\
\text { o mercado mundial; e de resultados tecnológicos, medidos pelo } \\
\text { total de patentes depositadas e concedidas ou de depósitos ou } \\
\text { registros de programas de computador em um determinado } \\
\text { período." (FURTADO et al., 2007, p. 13) }\end{array}$} & $\begin{array}{l}\text { Receita total de venda } \\
\text { de produtos novos } \\
\text { para a empresa }\end{array}$ \\
\hline & $\begin{array}{l}\text { Receita total de venda } \\
\text { de produtos novos para } \\
\text { o mercado nacional }\end{array}$ \\
\hline & $\begin{array}{l}\text { Receita total de venda } \\
\text { de produtos novos } \\
\text { para o mercado mun- } \\
\text { dial }\end{array}$ \\
\hline & $\begin{array}{l}\text { Total de patentes } \\
\text { depositadas }\end{array}$ \\
\hline & $\begin{array}{l}\text { Total de patentes } \\
\text { concedidas }\end{array}$ \\
\hline
\end{tabular}

Fonte: Adaptado de Furtado et al. (2007). 
A relação de indicadores do Quadro 2 está associada à investigação de Santos et al. (2012). Os autores propõem analisar a relação entre dois fatores - o grau intangibilidade e o grau de inovação em empresas inovadoras no Brasil -, cujo resultado foi o de que não há qualquer relação entre eles. A partir dos indicadores apresentados no Quadro 2 e do referencial teórico proposto, são levantadas as hipóteses correspondentes aos objetivos deste estudo. Levando-se em consideração os trabalhos de Santos et al. (2012) e Furtado et al. (2007), ainda propõe-se que a inovação tenha relação com a intangibilidade da empresa. Assim, tem-se:

H2: As categorias de P\&D, Projetos em Andamento, Marcas e Patentes, Licenças e Software possuem relação positiva com o total dos intangíveis das empresas (FURTADO et al., 2007).

H2: As categorias de P\&D, Projeto em Andamento, Marcas e Patentes, Licenças e Software não possuem relação positiva com o total dos intangíveis das empresas.

\subsection{Intangibilidade}

Segundo Kayo et al. (2006), os ativos intangíveis são um dos principais responsáveis pelas mudanças operacionais e financeira das empresas, resultando principalmente em uma crescente influência sobre seu o valor. Fonte disso é a constante utilização do índice Market-to-book, isto é, o índice do valor de mercado/valor contábil como indicador do nível de intangibilidade de uma empresa. Além disso, Kayo et al. (2006) ressaltam que os determinantes que mais se sobressaem no quesito de intangibilidade nas empresas brasileiras, em média, são o tamanho. Isto é, quanto maior a empresa, no que tange ao valor de mercado, maior a probabilidade de ela ser intangível-intensiva, e de forma inversamente proporcional ocorre, quando se trata do determinante do endividamento, isto é, quanto mais a empresa é intangível-intensiva, mais baixo é seu grau de endividamento.

Apesar disso, o registro de intangível no Balanço Patrimonial se tornou obrigatório apenas em 2007, por meio da Lei n. 11.638/2007 (BRASIL, 2007), a qual estabelece que ele deve ser apresentado no ativo não circulante. Em colaboração à lei, o CPC 04 (CPC, 2010) foi emitido, exigindo e promulgando o adequado tratamento contábil 
dos ativos intangíveis, bem como demonstrando as formas padrões de se mensurar e apresentar o valor contábil deles.

Os ativos intangíveis são vistos por um prisma amplo acerca de suas possibilidades de lucratividade e gestão de competência para as empresas. Conforme Arrighettia, Landinib e Lasagnia (2014), englobam o estoque de recursos imateriais que caracterizam o processo de produção de novos produtos e/ou processos e que, atrelado a isso, conforme De (2014), auxiliam na geração do lucro. Dessa forma, os ativos intangíveis revelam-se como um fator elementar no comportamento econômico da empresa e que podem ser levados em consideração por acionistas como um item relevante para futuros investimentos e resultados da empresa (PEREZ; FAMÁ, 2006; ANTUNES; LEITE, 2008).

Por fim, Lev (2001) propõe que os intangíveis, ou seja, formas não materialmente físicas e nem financeiras (patentes, marcas, títulos de divida, softwares e outros), estão englobadas em três categorias inovação, estrutura organizacional exclusiva e recursos humanos. Estas (particularmente a inovação) agregam referência à noção de Lev (2001) de que o principal interesse por parte das empresas pelo ativo intangível é decorrente do atual desenvolvimento e globalização que, perdurando por tantos anos, modificou significativamente as estruturas delas. As organizações buscam, cada vez mais, a agregação de valor por meio de ativos intangíveis, principalmente no quesito de novas tecnologias, isto é, a inovação tecnológica. Logo, propõem-se:

H3: O ativo intangível possui relação positiva com a lucratividade das empresas (LEV, 2001).

H3: O ativo intangível não possui relação positiva com a lucratividade das empresas.

H4: A diversificação dos intangíveis possui relação positiva com a lucratividade das empresas (LEV, 2001).

H4: A diversificação dos intangíveis não possui relação positiva com a lucratividade das empresas.

\section{MÉTodo}

O presente estudo consiste em uma pesquisa descritiva realizada a partir do levantamento de dados por procedimentos biblio- 
gráficos e documentais. Triviños (1987) indica que ela se classifica como qualitativa, pois são feitas inferências qualitativas na estruturação das categorias de estudo. Contudo, no âmbito dessa pesquisa a análise qualitativa tem apoio quantitativo. Cooper e Schindler (2011) complementam a aplicação dos dois métodos conjugados aumentando a qualidade dos dados de conclusão do estudo.

Nesse sentido, a população escolhida para fazer parte desse estudo, portanto, é composta pelas companhias de capital aberto devido à obrigatoriedade de apresentação de demonstrações financeiras e contábeis e notas explicativas, conforme previsto na Lei n. 6.404/1976 (BRASIL, 1976) e alterações subsequentes. Portanto, o universo do estudo é representado pelas empresas listadas na BM\&FBovespa.

O método de amostragem utilizado foi não probabilístico por julgamento. "A amostragem por julgamento acontece quando um pesquisador escolhe membros da amostra para atender a determinados critérios (COOPER; SCHINDLER, 2011). O critério para amostragem, portanto, consistiu primeiramente em desconsiderar as empresas que não apresentaram quadros de ativo imobilizado e de ativo intangível nas notas explicativas correspondentes ao encerramento do exercício selecionado como objeto de estudo. Dessa forma, permaneceram 262 companhias. Por fim, devido ao fato de a proposta deste estudo consistir em empresas que possuem caráter inovador, foram selecionadas apenas aquelas correspondentes ao segmento de novo mercado (NM) categorizado pela BM\&FBovespa, chegando ao número de 109.

Definida a seleção objeto de estudo, duas empresas foram excluídas por não possuírem o segmento informado, uma foi removida por ter seu capital encerrado e outras três foram removidas por distorcer as estatísticas (outlier), restando, portanto, 103 empresas. Para fins de análise dos dados, as empresas selecionadas foram divididas em quatro grupos de forma semelhante a Furtado et al. (2007), conforme apresentado no Quadro 3. 
Quadro 3: Distribuição da amostra da pesquisa

\begin{tabular}{|c|c|c|c|}
\hline $\begin{array}{l}\text { Grupo de Ino- } \\
\text { vação do IBI }\end{array}$ & Atividades CNAE 2.0 - PINTEC 2005 & $\begin{array}{l}\text { Segmento/setor } \\
\text { econômico cor- } \\
\text { respondente na } \\
\text { BM\&F Bovespa } \\
\text { com empresas } \\
\text { listadas }\end{array}$ & $\begin{array}{l}\text { Número } \\
\text { de em- } \\
\text { presas } \\
\text { lista- } \\
\text { das na } \\
\text { Bolsa }\end{array}$ \\
\hline $\begin{array}{l}\text { Grupo } 1 \\
\text { (alta tecnolo- } \\
\text { gia) }\end{array}$ & $\begin{array}{l}\text { Fabricação de outros equipamentos de } \\
\text { transporte, atividades de informática e } \\
\text { serviços relacionados, instrumentação } \\
\text { e automação industrial, máquinas para } \\
\text { escritório e equipamentos de informáti- } \\
\text { ca, fabricação de máquinas, aparelhos e } \\
\text { materiais elétricos e veículos, reboques } \\
\text { e carrocerias }\end{array}$ & $\begin{array}{l}\text { Material de } \\
\text { transporte, } \\
\text { computadores } \\
\text { e equipamen- } \\
\text { tos, máquinas e } \\
\text { equipamentos } \\
\text { e programas e } \\
\text { serviços }\end{array}$ & 30 \\
\hline $\begin{array}{l}\text { Grupo } 2 \\
\text { (média-alta } \\
\text { intensidade } \\
\text { tecnológica) }\end{array}$ & $\begin{array}{l}\text { Eletrônica e aparelhos e equipamentos } \\
\text { para telecomunicações, refino de petró- } \\
\text { leo e álcool, fabricação de máquinas e } \\
\text { equipamentos, fabricação de produtos } \\
\text { químicos, telecomunicações e fabrica- } \\
\text { ção de móveis e indústrias diversas }\end{array}$ & $\begin{array}{l}\text { Petróleo, gás e } \\
\text { biocombustí- } \\
\text { veis, químicos, } \\
\text { telecomunica- } \\
\text { ções e diversos }\end{array}$ & 17 \\
\hline $\begin{array}{l}\text { Grupo } 3 \\
\text { (média-baixa } \\
\text { intensidade } \\
\text { tecnológica) }\end{array}$ & $\begin{array}{l}\text { Fabricação de artigos de borracha e } \\
\text { plástico, fabricação de produtos de } \\
\text { minerais não metálicos, couros, cal- } \\
\text { çados e fabricação de artefatos de } \\
\text { couro, fabricação de produtos do fumo, } \\
\text { fabricação de celulose, papel e produ- } \\
\text { tos de papel, confecção de artigos do } \\
\text { vestuário e acessórios e fabricação de } \\
\text { produtos têxteis }\end{array}$ & $\begin{array}{l}\text { Materiais de } \\
\text { construção, te- } \\
\text { cidos, vestuário } \\
\text { e calçados, ci- } \\
\text { garros e fumo, } \\
\text { papel e celulo- } \\
\text { se e diversos }\end{array}$ & 25 \\
\hline $\begin{array}{l}\text { Grupo } 4 \\
\text { (baixa intensi- } \\
\text { dade tecnoló- } \\
\text { gica) }\end{array}$ & $\begin{array}{l}\text { Fabricação de produtos de metal, } \\
\text { indústrias extrativas, metalurgia básica, } \\
\text { fabricação de produtos de madeira, } \\
\text { fabricação de produtos alimentícios e } \\
\text { bebidas e edição, impressão e reprodu- } \\
\text { ção de gravações }\end{array}$ & $\begin{array}{l}\text { Utensílios do- } \\
\text { mésticos, mine- } \\
\text { rais metálicos, } \\
\text { siderurgia e } \\
\text { metalurgia, ma- } \\
\text { deira, diversos } \\
\text { e mídia }\end{array}$ & 31 \\
\hline
\end{tabular}

Fonte: Adaptado de Furtado et al. (2007). 
A coleta e organização dos dados seguiu o Quadro 3. Destaca-se que as notas explicativas das empresas foram utilizadas como referência para a categorização dos intangíveis e para determinar o valor total deste. Tal categorização seguiu os pressupostos teóricos (FURTADO et al., 2007; SANTOS et al. 2012) e utilizou por base as informações existentes nas notas explicativas. Os demais dados financeiros foram retirados diretamente do site BM\&FBovespa (BM\&FBOVESPA, [s.d.]), o qual disponibiliza essas informações de forma pública.

Para a análise dos dados foram utilizados os softwares Microsoft Excel e Statistical Package for the Social Sciences (SPSS), os quais permitiram identificar as médias, desvios, valores totais e foram responsáveis pela organização visual dos dados.

\section{ANÁlise dos RESUltados}

\subsection{Enfoque quantitativo}

Os resultados obtidos evidenciaram a relevância dos investimentos em software, ágio e marcas e patentes, que juntos representam mais de $50 \%$ dos totais de intangíveis. Tal informação reforça os achados de Santos et al. (2012) de que essas categorias representam o mainstream dos intangíveis. O Gráfico 1 demonstra a distribuição de frequência de cada categoria considerada no estudo, compreendendo com isso o primeiro objetivo específico deste trabalho. As categorias relacionadas à inovação, de acordo com o IBI (FURTADO et al., 2007), sendo softwares, marcas e patentes, P\&D, licenças e projetos em andamento, correspondem a 48,63\% dos intangíveis citados. Isso revela uma relação entre a intangibilidade e a inovação, porém apenas essas informações não são suficientes para indicar a influência de uma sobre a outra. 
Gráfico 1: Intangíveis por categoria

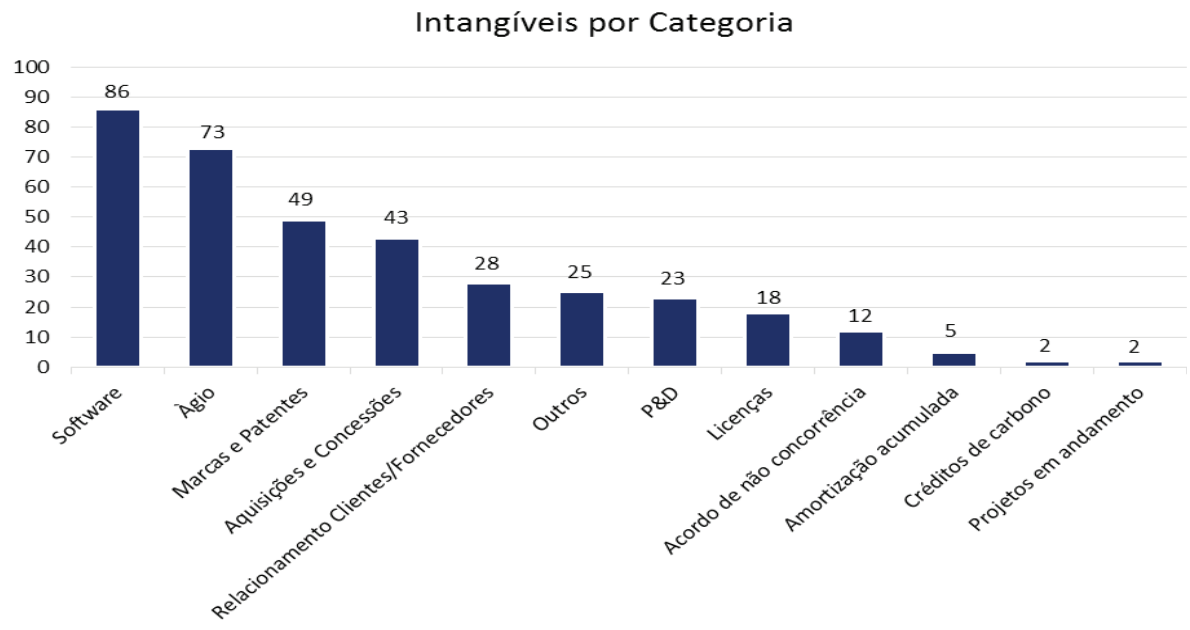

Fonte: Elaborado pelos autores.

Em relação ao critério financeiro da amostra, são descritas, por meio da Tabela 1, as estatísticas correspondentes ao ativo total, lucro líquido, patrimônio líquido, total de intangível e composição de intangíveis. Fica evidenciada a variedade de perfis de empresas, atribuindo um caráter de confiabilidade das generalizações obtidas por este estudo.

Tabela 1: Estatísticas descritivas

\begin{tabular}{llllll}
\hline & N & Mínimo & Máximo & Média & Desvio-padrão \\
\hline Lucro Líquido & 103 & $-328434,00$ & 1602820,00 & 129834,7961 & 263010,57386 \\
Total Intangível & 103 & 1020,00 & 21991922,00 & 1467862,7087 & 3155147,26303 \\
\hline Total Ativo & 103 & 268188,00 & 71269705,00 & 6913430,3010 & 9712718,06631 \\
\hline $\begin{array}{l}\text { Patrimônio } \\
\text { Líquido }\end{array}$ & 103 & $-9269885,00$ & 23294322,00 & 2675996,1748 & 4081155,68886 \\
\hline Qtde intangíveis & 103 & 1,00 & 7,00 & 3,5534 & 1,53858 \\
\hline N válido (de lista) & 103 & & & & \\
\hline
\end{tabular}

Fonte: Elaborado pelos autores.

De forma semelhante a Santos et al. (2012), não foram encontradas relações entre intangibilidade e inovação, pois algumas catego- 
rias consideradas inovadoras neste estudo, com base nos indicadores do IBI (FURTADO et al., 2007), sendo elas software e licenças, apresentaram correlação significativa com o total dos intangíveis; no entanto, as demais categorias - marcas e patentes, P\&D e projetos em andamento - não apresentaram correlação significativa. Dessa forma, a hipótese $\mathrm{H} 2$ levantada com base nos estudos de Furtado et al. (2007) não foi suportada.

Por outro lado, foi encontrada correlação entre a categoria de P\&D com o Lucro Líquido, evidenciando que a inovação possui relação com a lucratividade das empresas da amostra; entretanto, os testes de regressão não indicaram relações significativas, o que revela que a hipótese $\mathrm{H} 1$ proposta pelo Manual de Oslo (OECD, 2006) foi refutada. A Tabela 2 detalha esses achados.

Tabela 2: Correlações

\begin{tabular}{|c|c|c|c|c|c|c|c|c|c|c|c|c|c|c|c|c|c|}
\hline & & 1 & 2 & 3 & 4 & 5 & 6 & 7 & 8 & 9 & 10 & 11 & 12 & 1314 & 15 & 16 & 17 \\
\hline 1 & Total Ativo & 1 & & & & & & & & & & & & & & & \\
\hline 2 & Patrimônio & $911^{* *}$ & 1 & & & & & & & & & & & & & & \\
\hline 3 & Lucro Líquido &, $535^{* *}$ &, $537^{* *}$ & 1 & & & & & & & & & & & & & \\
\hline 4 & Total Intangível & ,674, & $671^{* *}$ & $467^{* *}$ & 1 & & & & & & & & & & & & \\
\hline 5 & $\begin{array}{l}\text { Acordo de não } \\
\text { concorrência }\end{array}$ &,- 048 &,- 010 & ,117 &,- 035 & 1 & & & & & & & & & & & \\
\hline 6 & Ágio & ,052 & ,068 &,- 181 &,- 049 &,- 034 & 1 & & & & & & & & & & \\
\hline 7 & $\begin{array}{l}\text { Amortização } \\
\text { acumulada }\end{array}$ &,- 088 &,- 070 &,- 088 &,- 098 & ,059 &,$- 253^{* *}$ & 1 & & & & & & & & & \\
\hline 8 & $\begin{array}{l}\text { Aquisições e } \\
\text { Concessões }\end{array}$ & 085 & 052 &,- 022 & $222^{*}$ & 061 &,- 064 &,- 100 & 1 & & & & & & & & \\
\hline 9 & $\begin{array}{l}\text { Créditos de } \\
\text { carbono }\end{array}$ &,- 035 &,- 046 & ,066 &,- 054 &,- 051 &,- 065 &,- 032 & 166 & 1 & & & & & & & \\
\hline 10 & Licenças & 078 & 138 & 057 & $207^{*}$ & -087 & ,014 & 015 & -,027 & -065 & 1 & & & & & & \\
\hline 11 & $\begin{array}{l}\text { Marcas e } \\
\text { Patentes }\end{array}$ &,- 017 & 017 & 008 &,- 061 &, $260^{* *}$ & ,012 & ,056 & ,021 & 148 &,- 029 & 1 & & & & & \\
\hline 12 & P\&D &,- 020 &,- 044 & , 208 & 127 & 169 &,- 067 &,- 013 & $208^{*}$ & 093 & 122 & -091 & 1 & & & & \\
\hline 13 & $\begin{array}{l}\text { Projetos em } \\
\text { andamento }\end{array}$ & 120 & 171 & 126 & 075 &,- 051 & ,090 &,- 032 &,- 119 &,- 020 & 121 &,- 134 & 093 & 1 & & & \\
\hline 14 & $\begin{array}{l}\text { Relacionamento } \\
\text { Clientes/ } \\
\text { Fornecedores }\end{array}$ & ,232* & , $241^{*}$ & 163 & 179 &, 526 & ,055 & 065 & -031 & ,072 & 006 & , 336 & ,039 & , 072 1 & & & \\
\hline 15 & Software &,- 065 &,- 083 & 111 &,$- 240^{*}$ &,- 002 & ,003 &,- 021 &,- 154 & 063 &,$- 415^{* *}$ & 057 &,- 013 & ,063 - 022 & 1 & & \\
\hline 16 & Outros & 122 & 090 & 011 & 003 & ,077 & , 263 &,- 128 & 164 &,- 080 &, $217^{*}$ & ,096 &,- 086 & 112, 084, & ,008 & 1 & \\
\hline 17 & Qtde intangíveis & , 122 & 139 & ,119 & 099 & ,501* & ,315 & ,036 &, $363^{* *}$ & 179 & $218^{*}$ &, $506^{* *}$ &, $354^{* *}$ & 133, 577" & 109 &, $505^{* *}{ }_{1}$ & \\
\hline
\end{tabular}

*. A correlação é significativa no nível 0,05 (2 extremidades).

**. A correlação é significativa no nível 0,01 (2 extremidades).

Fonte: Elaborado pelos autores. 


\subsection{Enfoque qualitativo}

A hipótese H3 de Lev (2001) não foi suportada, pois mesmo encontrada uma correlação significativa entre o total dos intangíveis e o lucro líquido, o teste- $t$ de uma amostra não apresentou resultado que indique uma possível regressão entre esses termos (MARTINS; DOMINGUES, 2011). Dessa forma, infere-se que os investimentos em intangíveis tendem a influenciar positivamente o lucro líquido das empresas, mas não é possível indicar uma relação de causa e efeito. O mesmo efeito foi encontrado para o total dos ativos e patrimônio líquido. Assim como as demais, a hipótese H4 de Lev (2001) não foi suportada, pois a quantidade de intangíveis por empresa não apresentou relação com a lucratividade (Tabela 3).

Tabela 3: Teste-t de uma amostra

\begin{tabular}{|c|c|c|c|c|c|c|}
\hline & \multicolumn{6}{|c|}{ Valor de Teste $=0$} \\
\hline & \multirow[t]{2}{*}{$t$} & \multirow[t]{2}{*}{ df } & \multirow{2}{*}{$\begin{array}{l}\text { Sig. }(2 \\
\text { extremi- } \\
\text {-dades) }\end{array}$} & \multirow{2}{*}{$\begin{array}{l}\text { Diferença } \\
\text { média }\end{array}$} & \multicolumn{2}{|c|}{$\begin{array}{l}\text { 95\% Intervalo de Confiança da } \\
\text { Diferença }\end{array}$} \\
\hline & & & & & Inferior & Superior \\
\hline Lucro Líquido & 4,473 & 95 &, 000 & 84787,25000 & 47154,4581 & 122420,0419 \\
\hline Total Intangível & 6,083 & 95 & ,000 & 855996,95833 & 576632,1312 & 1135361,7854 \\
\hline Total Ativo & 8,924 & 95 & ,000 & 5156068,22917 & 4009098,9938 & 6303037,4646 \\
\hline Patrimônio Líquido & 7,213 & 95 & ,000 & 1947944,72917 & 1411826,7482 & 2484062,7101 \\
\hline
\end{tabular}

Fonte: Elaborado pelos autores.

Os resultados apresentados demonstraram que os investimentos em intangíveis da categoria de relacionamento com clientes e consumidores tiveram uma relação significativa com o patrimônio líquido e total de ativos. Essa relação indica um direcionamento dessa categoria para o desempenho organizacional, no entanto não foi evidenciada relação direta entre esses construtos. Dessa forma, os resultados quantitativos não permitiram isoladamente a compreensão da relação entre os investimentos em ativos intangíveis com a inovação; para tal foi apresentado um enfoque qualitativo do estudo que relaciona os resultados dos grupos tecnológicos (FURTADO et al., 2007) objetivando a compreensão do vínculo entre o intangível com o grau de complexidade tecnológica das organizações. 
As empresas do grupo 1 (alta tecnologia) apresentaram $11,76 \%$, e as do grupo 2 (média-alta tecnologia), 11,49\% dos investimentos em intangíveis na categoria de Marcas e Patentes. Isso representa a pouca notoriedade dada à inovação por essas empresas comparada às de menor grau de tecnologia, que tiveram 17,05\% no grupo 3 (média-baixa tecnologia) e 12,84\% no grupo 4 (baixa tecnologia). Tais informações podem ser explicadas pela tentativa de aproximação de tecnologia das empresas dos grupos 3 e 4 que necessitam de maiores investimentos em inovação para competirem com as demais. A relação obtida com a categoria de software não evidenciou variações entre os grupos - os grupos 1, 2, 3, e 4 foram respectivamente por $24,51 \%, 20,9 \%, 23,86 \%$ e $23,85 \%$.

Vale ressaltar que foi aplicada também uma análise de equações estruturais, controlando os multigrupos (alto, médio e baixo) de inovação tecnológica. Todavia, nenhuma relação foi significativa. Foram testadas as relações \% intangível x \% lucro, ou nível de inovação x \% lucro, e \% intangível x nível de inovação. Também foram testadas essas relações de forma direta no SPSS, fazendo Anova, a fim de verificar se havia diferença entre os grupos, mas não resultou dados significativos. Logo, investir em ativos intangíveis não aumenta a lucratividade nas empresas de novo mercado, ao menos se analisado um único exercício.

\section{CONSIDERAÇõES FINAIS}

Por meio deste estudo foi possível compreender as relações entre as categorias de intangíveis e as informações contábeis de ativo total, patrimônio líquido, lucro líquido e valor total de intangíveis por meio da quantificação da frequência com que ocorrem nas empresas de novo mercado, cabendo essa compreensão a esse grupo específico de companhias. O estudo também identificou a influência das categorias tidas como inovadoras de acordo com os indicadores do IBI (FURTADO et al., 2007) por meio dos estudos de correlação entre as categorias inovadoras com os investimentos em intangíveis das empresas estudadas.

Foi possível identificar a frequência com que cada categoria é declarada, ressaltando a relevância de intangíveis como software, ágio e marcas e patentes, declarados por 53\% das empresas estuda- 
das. A complexidade dos intangíveis, portanto, é destacada mediante a variedade de estudos realizados, nos quais não foram encontradas relações significativas que indiquem causalidade.

Os resultados obtidos, embora semelhantes a Santos et al. (2012), contribuem para reforçar a existência de uma relação tênue entre o grau de inovação e o de intangibilidade de uma organização. Tal relação é indicada por meio das correlações encontradas entre o intangível total e as categorias de software, marcas e patentes, P\&D, aquisições e concessões, licenças e projetos em andamento, assim como pela frequência dessas categorias. Os resultados identificaram uma correlação positiva dos investimentos em intangíveis com a lucratividade de uma organização; todavia, assim como a relação dos investimentos em intangíveis com a inovação, não foi possível identificar relações de causalidade por meio dos testes estatísticos, o que significa que não é possível generalizar esses achados.

Embora as hipóteses levantadas com base no referencial teórico tenham sido refutadas, este estudo contribui teoricamente para compreensão da influência dos intangíveis no contexto organizacional, fornecendo evidências empíricas para futuras pesquisas, e também metodologicamente, utilizando o instrumental estatístico para identificar essas influências. A limitação deste estudo consiste em que apenas as empresas que disponibilizam o quadro de intangíveis puderam ser estudadas, desconsiderando elementos que possam reforçar essas relações. Para pesquisas futuras são sugeridos estudos de caso que aprofundem as informações de um caso específico para compreender as relações desses intangíveis em um nível micro de análise e, dessa forma, perceber nuances não encontradas em análise em níveis meso ou macro, assim como perspectivas qualitativas que expressem a influência dos intangíveis para sujeitos distintos.

\section{REFERÊNCIAS}

ANTUNES, M. T. P.; LEITE, R. S. Divulgação de informações sobre ativos intangíveis e sua utilidade para analistas de investimentos. Revista Universo Contábil, Blumenau, v. 4, n. 4, p. 22-38, out./dez. 2008.

ARDICHVILI, A.; CARDOZO, R.; RAY, S. A theory of entrepreneurial opportunity identification and development. Journal of Business Venturing, v. 18, n. 1, p. 105-123, 2000. 
ARRIGHETTIA, A. LANDINIB, F. LASAGNIA, A. Intangible assets and firm heterogeneity: Evidence from Italy. Research Policy, v. 43, n. 1, p. 202-213, fev. 2014.

BM\&F BOVESPA. Site oficial. [S.d.]. Disponível em: <http://www.bmfbovespa.com.br/> Acesso em: 20 nov. 2014.

BRASIL. Lei n. 11.638, de 28 de dezembro de 2007. Diário Oficial da União, Poder Legislativo, Brasília, 29 dez. 2007. Disponível em: <http://www.planalto.gov.br/ccivil_03/_ato20072010/2007/Lei/L11638.htm>. Acesso em: 27 nov. 2014.

. Lei no 6.404, de 15 de dezembro de 1976. Diário Oficial da União, Poder Legislativo, Brasília, DF, 16 dez. 1976. Disponível em: <http://www.planalto.gov.br/ccivil_03/leis/ 16404consol.htm>. Acesso em: 16 nov. 2014.

.. Lei $\mathrm{n}^{\circ} 10.973$, de 2 de dezembro de 2004. Dispõe sobre incentivos à inovação e à pesquisa científica e tecnológica no ambiente produtivo e dá outras providências. Diário Oficial da União, Poder Legislativo, Brasília, DF, 02 dez. 2004. Disponível em: < http://www. normaslegais.com.br/legislacao/lei10973.htm>. Acesso em: 16nov. 2014.

CLEMENTE, R. G.; CAULLIRAUX, H. M. Inovação: novas abordagens e suas implicações para as PMEs. In: ENCONTRO REINC, 10., Rio de Janeiro, 8-9 nov. 2007. Anais... Rio de Janeiro: Redetec, 2007.

CPC - COMITÊ DE PRONUNCIAMENTOS CONTÁBEIS. Pronunciamento Técnico CPC 04 - Ativo Intangível. Brasília, 2010. Disponível em: <http://static.cpc.mediagroup.com.br/ Documentos/187_CPC_04_R1_rev\%2003.pdf> Acesso em: 20 nov. 2014.

COOPER, D. R.; SCHINDLER, P. S. Métodos de Pesquisa em Administração. 10. ed. Porto Alegre: Bookman, 2011.

DE, S. Intangible capital and growth in the 'new economy': Implications of a multi-sector endogenous growth model. Structural Change and Economic Dynamics, v. 28, p. 25-42, mar. 2014.

FURTADO, A. et al. Índice Brasil de Inovação: manual informativo sobre o procedimento de adesão das empresas. Campinas: UNICAMP/IG/DPCT; LABJOR, 2007.

GUIMARÃES, S. K. Empreendedorismo intensivo em conhecimento no Brasil. Caderno CRH, Salvador, v. 24, n. 63, p. 575-591, 2011.

HANSEN, D. J.; SHRADER, R.; MONLLOR, J. Defragmenting Definitions of Entrepreneurship Research: Past Accomplishments and Future Challenges. Journal of Small Business Management, v. 49, n. 2, p. 283-304, 2011.

IBGE - INSTITUTO BRASILEIRO DE GEOGRAFIA E ESTATÍSTICA. Pesquisa de Inovação 2011. Rio de Janeiro: IBGE, 2013. Disponível em: <http://www.pintec.ibge.gov.br/downloads/ pintec2011\%20publicacao\%20completa.pdf> Acesso em: 16 nov. 2014.

KAYO, E. K. et al. Os fatores determinantes da intangibilidade. Revista de Administração Mackenzie, São Paulo, v. 7, n. 3, p. 112-130, 2006.

KIRZNER, I. The Alert and creative entrepreneur: a clarification. Small Business Economics, v. 32, p. 145-152, 2008. 
LEV, B. Intangibles: management, measurement and reporting. Washington: Brookings Institution Press, 2001.

MARTINS, G. A.; DOMINGUES, O. Estatística Geral e Aplicada. 4. ed. São Paulo: Atlas, 2011. MATIAS-PEREIRA, J.; KRUGLIANSKAS, I. Gestão de inovação: a lei de inovação tecnológica como ferramenta de apoio às políticas industrial e tecnológica do Brasil. RAE-eletrônica, v. 4, n. 2, jul./dez., 2005.

MONTRESOR, S.; PERANI, G.; VEZZANI, A. How do companies 'perceive' their intangibles? New statistical evidence from the innobarometer 2013. Institute for Prospective Technological Studies. European Commission 2014. Disponível em: <ftp://ftp.jrc.es/pub/EURdoc/EURdoc/ JRC88865.pdf> Acesso em: 17 maio 2014.

OCDE - ORGANIZAÇÃO PARA A COOPERAÇÃO E DESENVOLVIMENTO ECONÔMICO. Manual de Oslo: diretrizes para a coleta e interpretação de dados sobre inovação. 3. ed. Brasília: FINEP, 2006.

PEREZ, M. M.; FAMÁ, R. Ativos intangíveis e o desempenho empresarial. Revista Contabilidade \& Finanças, São Paulo, v. 17, n. 40, p. 7-24, 2006.

QUADROS, R.; FURTADO, A. Índice Brasil de Inovação: a próxima etapa. Inovação Uniemp, Campinas, v. 3, n. 5, set./out. 2007. Disponível em: <http://inovacao.scielo.br/scielo. php?script=sci_arttext\&pid=S1808-23942007000500014>. Acesso em: 30 nov. 2014.

SANTOS, J. G. C. et al. Intangibilidade e inovação em empresas no Brasil. Revista de Administração e Inovação, São Paulo, v. 9, n. 2, p. 198-222, 2012.

SCHUMPETER, J. A. Capitalism, Socialism, and Democracy. 3. ed. New York: Harper and Brothers, 1950.

TRIVIÑOS, A. N. S. Introdução à pesquisa em ciências sociais: a pesquisa qualitativa em educação. São Paulo: Atlas, 1987.

TSAI, C.-F.; LUB; Y-H. C. Determinants of intangible assets value: The data mining approach. Knowledge-Based Systems, v. 31, p. 67-77, jul. 2012.

Recebido em: 30-1-2017

Aprovado em: 4-05-2017

Avaliado pelo sistema double blind review.

Editor: Elmo Tambosi Filho

Disponível em http://mjs.metodista.br/index.php/roc 